\title{
Thermal Conductivity and Photothermal Conversion Performance of Ethylene Glycol-Based Nanofluids Containing Multiwalled Carbon Nanotubes
}

\author{
Nguyen Trong Tam, ${ }^{1,2,3}$ Pham Van Trinh $\mathbb{D}^{1},{ }^{1}$ Nguyen Ngoc Anh, ${ }^{1}$ Nguyen Tuan Hong, \\ Phan Ngoc Hong, ${ }^{2,4}$ Phan Ngoc Minh $(1),{ }^{1,2,4}$ and Bui Hung Thang $\left(\mathbb{D}^{1}\right.$ \\ ${ }^{1}$ Institute of Materials Science, Vietnam Academy of Science and Technology, 18 Hoang Quoc Viet Str., Cau Giay Distr, \\ Hanoi, Vietnam \\ ${ }^{2}$ Graduate University of Science and Technology, Vietnam Academy of Science and Technology, 18 Hoang Quoc Viet Str., \\ Cau Giay Distr, Hanoi, Vietnam \\ ${ }^{3}$ Department of Physics, Faculty of Basic-Fundamental Sciences, Vietnam Maritime University, 484 Lach Tray Road, Le Chan, \\ Hai Phong, Vietnam \\ ${ }^{4}$ Center for High Technology Development, Vietnam Academy of Science and Technology, 18 Hoang Quoc Viet Str., Cau Giay Distr, \\ Hanoi, Vietnam
}

Correspondence should be addressed to Pham Van Trinh; trinhpv@ims.vast.vn and Bui Hung Thang; thangbh@ims.vast.ac.vn

Received 15 May 2018; Revised 19 September 2018; Accepted 23 September 2018; Published 22 November 2018

Academic Editor: Giuseppe Compagnini

Copyright (c) 2018 Nguyen Trong Tam et al. This is an open access article distributed under the Creative Commons Attribution License, which permits unrestricted use, distribution, and reproduction in any medium, provided the original work is properly cited.

\begin{abstract}
In this study, the successful hydroxyl functionalization of carbon nanotubes (MWCNT-OH) was prepared by chemical treatments and characterized by Raman and FTIR spectra. MWCNT-OH was successfully dispersed into ethylene glycol (EG) with the Tween-80 surfactant by an ultrasonication method to prepare nanofluids. Thermal conductivity of nanofluid was investigated, and a maximum thermal conductivity enhancement about $24 \%$ at $50^{\circ} \mathrm{C}$ was obtained with nanofluid containing 0.64 vol.\% MWCNT concentration. The photothermal conversion performance of nanofluid was also investigated by measuring the change of the temperature under lighting from a solar simulator. The measurement results showed that the highest photothermal conversion was obtained about $4.2 \%$ after a 30 min lighting with nanofluid containing 0.48 vol. $\%$ CNT concentration compared to ethylene glycol. These obtained results have propose a potential application of CNTs in nanofluids for solar absorption.
\end{abstract}

\section{Introduction}

The demands for new clean energy sources like wind energy and solar energy are very high to replace the traditional energy sources. Many organizations and researchers around the world have been focusing on this problem and trying to find the best solution for the energy security in the future. Solar energy conversion is widely used to generate heat and produce electricity, in which heat generation is a method that does not require microelectronic technology and thus possibly proposes an energy solution with a reasonable price compared to others [1-5]. The problem here is the working fluid with low thermal conductivity in solar collectors not good enough to capture incident solar radiations and convert it into thermal energy. Recently, a new class of fluids called nanofluid including nanomaterials like nanoparticles, nanotubes, nanowires, nanorods, and nanosheet in base fluids improved the thermophysical properties like thermal conductivity, electrical conductivity, viscosity, and convective heat transfer coefficients compared to the traditional base 
fluids such as water and ethylene glycol [5-7]. Besides, the nanofluids possibly propose a higher surface area for solar energy and heat absorption processes. In addition, the included nanomaterials with selective absorption spectrum possibility and thus nanofluids combined different materials can absorb sunlight in a wide range from ultraviolet to infrared $[8,9]$.

Carbon nanotubes (CNTs), a well-known material with many excellent properties such as high thermal conductivity and high electrical conductivity, have been considered an ideal nanoadditive material for nanofluid applications [10-15]. Nanofluids containing CNTs have been investigated and developed by many researchers and manufacturers and expressed as a great candidate for many potential applications such as heat transfer, thermal dissipation, and solar energy absorption. The critical technical problem with CNT nanofluid is how to uniform disperse CNTs in base fluids like water and ethylene glycol to obtain not only good stability but also high performance $[16,17]$.

The two main methods including noncovalent functionalization and covalent functionalization were usually used to obtain the uniform dispersion and high stability of CNT-based nanofluids [18]. Noncovalent functionalization usually uses surfactants such as sodium dodecyl benzene sulfonate (SDBS), sodium dodecyl sulfate (SDS), Tween, and chitosan to improve the wettability between CNTs and based fluids. The earlier studies demonstrated the efficacy of noncovalent functionalization in preparing the high stability of CNT nanofluids [18]. Unlike, the covalent functionalization usually use functional groups including $\mathrm{COOH}, \mathrm{OH}$, and $\mathrm{NH} 2$ to eliminate the van der Waals forces among CNTs via hydrogen bonding between functional groups and base fluids and thus obtain high-stability nanofluids. Among the functional groups, the hydroxyl $(\mathrm{OH})$ group exhibited a higher interaction energy compared to others (CNT-OH $\left(116 \mathrm{kcal} \mathrm{mol}^{-1}\right)>\mathrm{CNT}-\mathrm{COOH}\left(80 \mathrm{kcal} \mathrm{mol}^{-1}\right)>\mathrm{CNT}=\mathrm{O}$ $\left.\left(70 \mathrm{kcal} \mathrm{mol}^{-1}\right)>\mathrm{CNT}=\mathrm{C}=\mathrm{O}\left(-36 \mathrm{kcal} \mathrm{mol}^{-1}\right)\right)$ [19]. Therefore, incorporating $\mathrm{CNT}-\mathrm{OH}$ with organic compounds including polymers and solvents could significantly improve all of the mechanical properties [20] and electrical and thermal properties [21].

Thus, the purpose of this work is to prepare and investigate for the first time EG-based nanofluids containing MWCNT that has good stability, high thermal conductivity, and high photothermal conversion performance by the combination of the surface modification of CNT with the hydroxyl functional group and Tween-80 surfactant.

\section{Experimental Procedure}

Multiwalled carbon nanotubes (MWCNTs) synthesized by a chemical vapor deposition (CVD) technique were used for preparing the nanofluids. Firstly, MWCNTs were treated with the mixture of $\mathrm{H}_{2} \mathrm{SO}_{4}$ and $\mathrm{HNO}_{3}$ with a volume ratio of $3: 1$ at $70^{\circ} \mathrm{C}$ for $5 \mathrm{~h}$. After that, as-received solution was cleaned by distilled water to obtain MWCNT-COOH. The obtained MWCNT-COOH was then suspended in $\mathrm{SOCl}_{2}$ solution to obtain MWCNT-COCl under continuous stirring for $6 \mathrm{~h}$ at $60^{\circ} \mathrm{C}$. The obtained solution was filtered, washed with THF and distilled water, and then mixed with EG for $8 \mathrm{~h}$ at $120^{\circ} \mathrm{C}$ to obtain the MWCNT-OH. Finally, the MWCNT-OH was dispersed in EG with 1 vol.\% Tween-80 surfactant to prepare MWCNT-EG nanofluids by ultrasonication. The prepared nanofluids are noted as NF1, NF2, and NF3 corresponding to the different CNT concentrations of $0.32,0.48$, and $0.64 \mathrm{vol} . \%$, respectively.

The morphology and microstructure of MWCNTs were investigated by scanning electron microscopy (FESEM, Hitachi S4800), transmission electron microscopy (HRTEM, Jeon-JEM 2100), Raman spectroscopy (iHR550 Jobin-Yvon spectrometer), and FTIR spectroscopy (Jasco FT/IR-4600). Thermal conductivity $(K)$ of nanofluids was measured in range from $30^{\circ} \mathrm{C}$ to $50^{\circ} \mathrm{C}$ with $\mathrm{HTL}-04$ equipment supplied by Eternal Engineering Equipment Ltd., India. The HTL-04 apparatus based on the principle of a guarded hot plate (GHP) method has a maximum uncertainty of $\pm 2 \%$. The photothermal conversion property of nanofluid was investigated by measuring directly the temperature of the MWCNT/EG nanofluid during lighting from a solar simulator. In our experiment, a xenon arc lamp was used as the lighting source because it can be filtered to have an emission spectrum closely matching that of terrestrial sunlight. The detail of the experimental setup for photothermal conversion measurement was shown in Figure 1.

\section{Results and Discussion}

Typical SEM and TEM images of MWCNTs are shown in Figure 2. It reveals that the MWCNTs have a uniform size with an average length of $10 \mu \mathrm{m}$ (Figure 2(a)). The detail of diameter distribution of MWCNTs was measured for about 150 CNTs as shown in Figure 2(b). The average outer diameter is equal to $20 \mathrm{~nm}$. HRTEM was performed to investigate the effect of the hydroxyl functionalization process on the structure of MWCNTs. As shown in Figure 2(c), as-received MWCNTs have a smooth surface with a d-spacing measured by ImageJ to be $0.34 \mathrm{~nm}$ similar to that of a graphite. In the case of MWCNT-OH, some structural defects were observed on the surface of MWCNT as etched positions and amorphous clusters (Figure 2(d)). The structural defects may be due to the effect of regents during the chemical functionalization process $[18,22]$. dspacing of MWCNT-OH measured to be $0.38 \mathrm{~nm}$ is larger than that of as-received MWCNTs. The obtained result implies that the presence of $\mathrm{OH}$ groups attached to the surface caused an increase in the d-spacing of MWCNTs. From the data, we can calculate the empirical shape factor $(n)$ of MWCNTs as

$$
n=\frac{3}{\psi}
$$

where $\psi$ is the sphericity of MWCNT and is defined as

$$
\psi=\frac{\pi^{1 / 3}\left(6 V_{p}\right)^{2 / 3}}{A_{p}}
$$




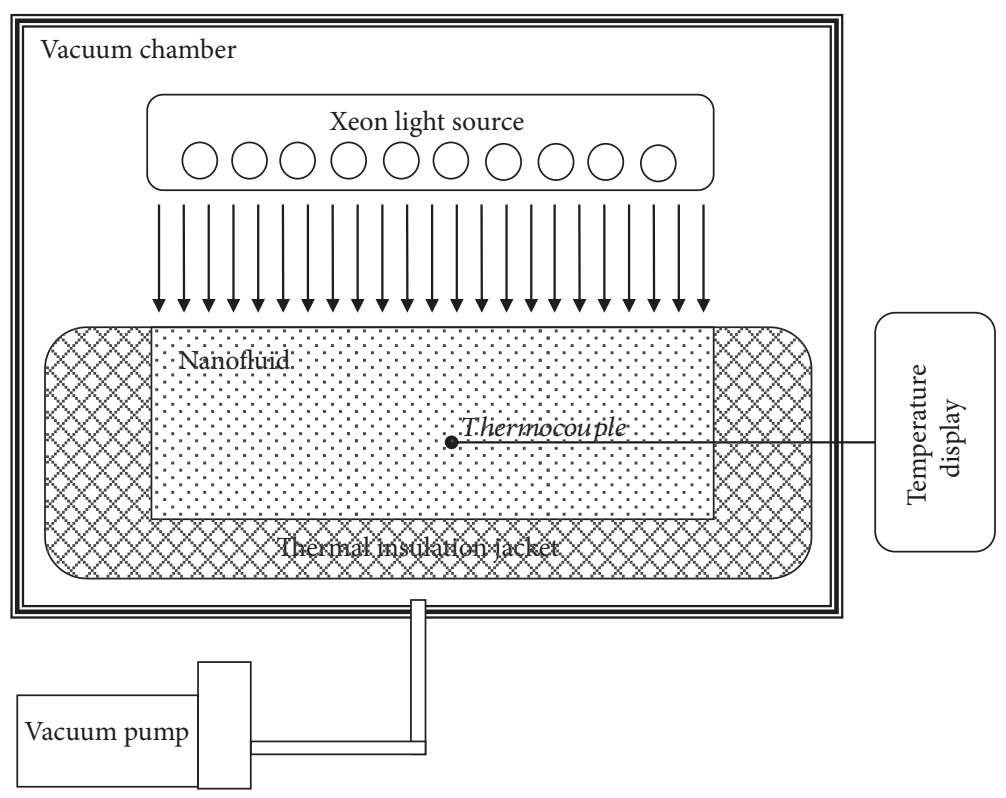

Figure 1

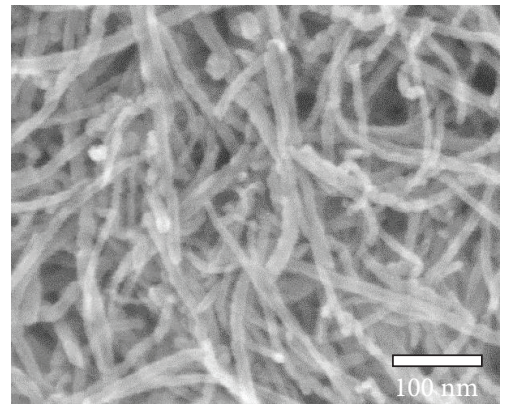

(a)

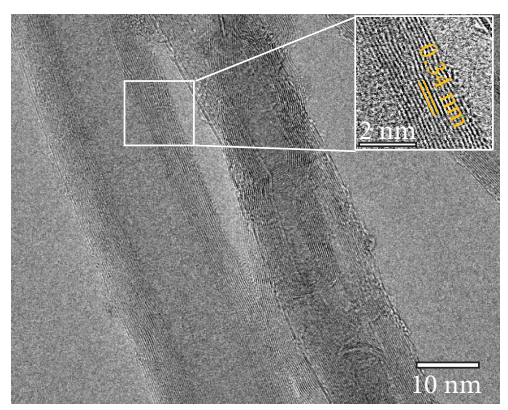

(c)

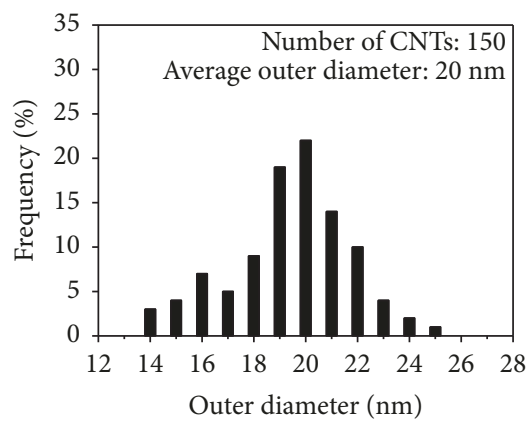

(b)

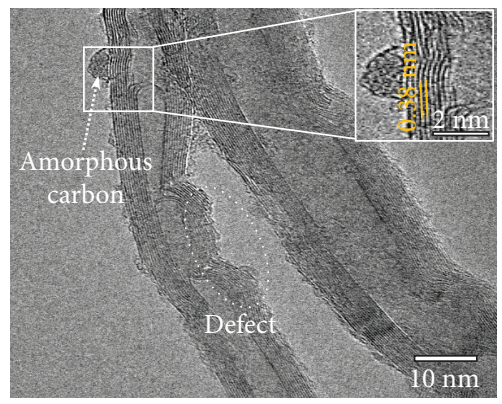

(d)

Figure 2

where $V_{p}$ and $A_{p}$ are the volume and the surface area of MWCNTs and are expressed as follows:

$$
\begin{gathered}
V_{p}=\pi r^{2} l, \\
A_{p}=2 \pi r(r+l),
\end{gathered}
$$

with $r=10 \mathrm{~nm}$ and $l=10 \mu \mathrm{m}$ for the radii and length of MWCNT; the empirical shape factor is determined to be approximately about 14 .

Figure 3(a) shows the Raman spectra of as-received MWCNT and MWCNT-OH. Typical bands at $1348 \mathrm{~cm}^{-1}$ and $1590 \mathrm{~cm}^{-1}$ are defined as a defect band (D) and a graphitic 


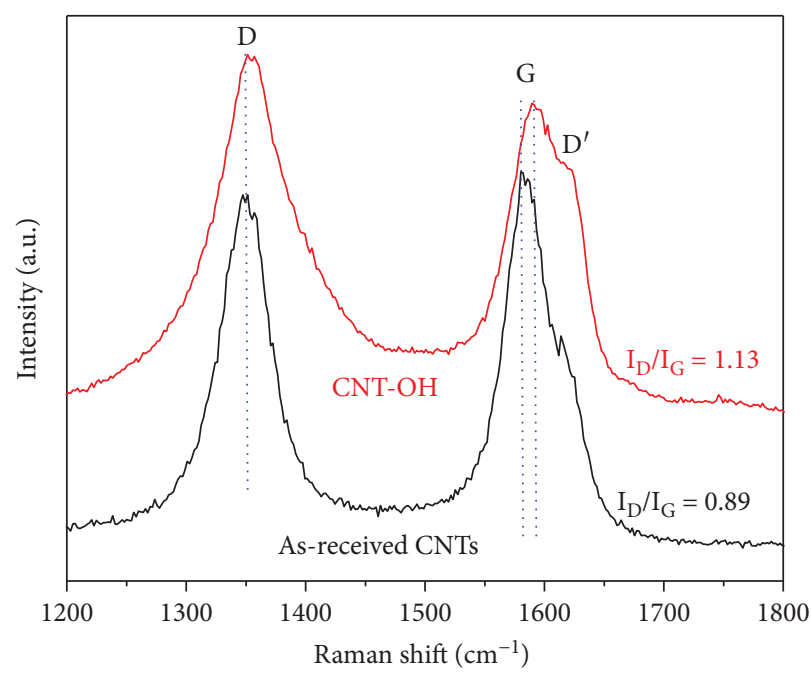

(a)

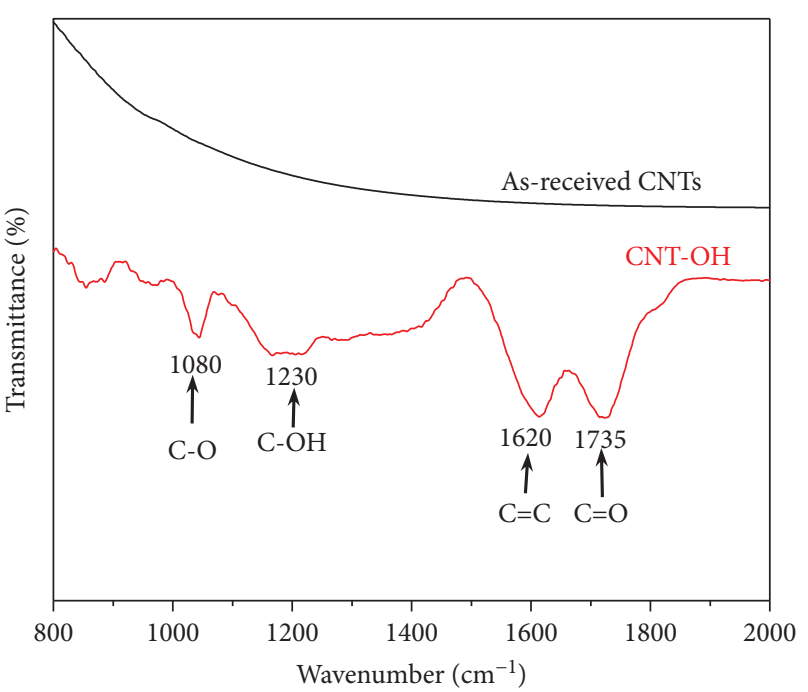

(b)

Figure 3

band $(G)$, respectively. As can be seen, the broadening of the $\mathrm{G}$ band of MWCNT-OH indicates a reduction in the resonance-induced vibration extinction time [23]. This could imply an increase in structural defects and/or a shortening of the CNT after the hydroxyl functionalization process. The G band positions upshift to a larger wavenumber with MWCNT-OH. This could be due to the increase in the amorphous carbon content resulting from a convolution between the original G band (approx. $1580 \mathrm{~cm}^{-1}$ ) and the D' band (approx. $1620 \mathrm{~cm}^{-1}$ ). In addition, according to Bokobza and Zhang, they reported that the upshift of the G band is due to the less intertube interactions between MWCNT$\mathrm{OH}$ meaning that the dispersion state of MWCNT-OH is improved [24]. The relative intensity ratio of $\mathrm{D}$ to $\mathrm{G}\left(I_{\mathrm{D}} / I_{\mathrm{G}}\right)$ also is an important parameter that needs to be considered for carbon nanomaterials. In this work, the $I_{\mathrm{D}} / I_{\mathrm{G}}$ was determined to be 0.89 and 1.13 corresponding to as-received MWCNTs and MWCNT-OH, respectively. The increase in the $I_{\mathrm{D}} / I_{\mathrm{G}}$ ratio of MWCNT-OH compared to that of as-received MWCNTs indicated that the chemical treatment for $\mathrm{OH}$ attachment strongly affected the CNT structure by inducing some defect points [25]. The Raman results are in good agreement with the HRTEM analysis as discussed earlier.

Figure 3(b) shows the FTIR spectra of MWCNTs and MWCNTs functionalized with $\mathrm{OH}$ groups. There are no peaks observed from FTIR spectra of as-received MWCNTs. It means that no functional groups were attached on the surface of MWCNT after the synthesis process. For MWCNT$\mathrm{OH}$, several peaks at $1735,1620,1230$, and $1080 \mathrm{~cm}^{-1}$ were observed and can be ascribed to stretching vibrations of $\mathrm{C}=\mathrm{O}, \mathrm{C}=\mathrm{C}, \mathrm{C}-\mathrm{OH}$, and $\mathrm{C}-\mathrm{O}$ bonds, respectively $[18,26]$. The obtained results confirmed that MWCNT-OH was successfully prepared by multistep chemical treatments.

The aggregate size distribution of the nanofluids containing different CNT concentrations is shown in Figure 4. As can be seen in Figure 4, the peak of aggregate size for

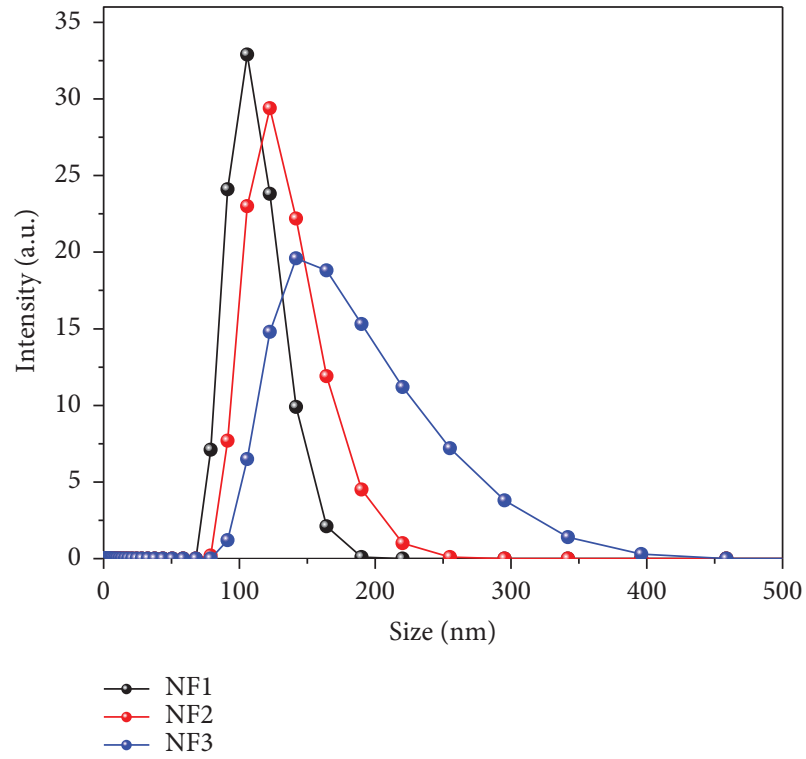

Figure 4

nanofluids increased as CNT concentrations increase. The aggregated size of the nanofluid was measured to be 110 $\mathrm{nm}, 125 \mathrm{~nm}$, and $150 \mathrm{~nm}$ corresponding to nanofluids NF1, NF2, and NF3, respectively. This result indicated that CNTs tend to aggregate together as the concentration in the solution increases. The zeta potential of the nanofluid was measured to be $-65 \mathrm{mV},-52.9 \mathrm{mV}$, and- $-47.2 \mathrm{mV}$ for nanofluids NF1, NF2, and NF3, respectively. It is well known that a nanofluid has good stability if it has an absolute zeta potential value above $30 \mathrm{mV}[27,28]$. As a result, the prepared EG-based nanofluids containing MWCNT-OH and Tween-80 surfactant have good stability.

Figure 5 shows the thermal conductivity enhancement of nanofluids with different MWCNT concentrations as a 


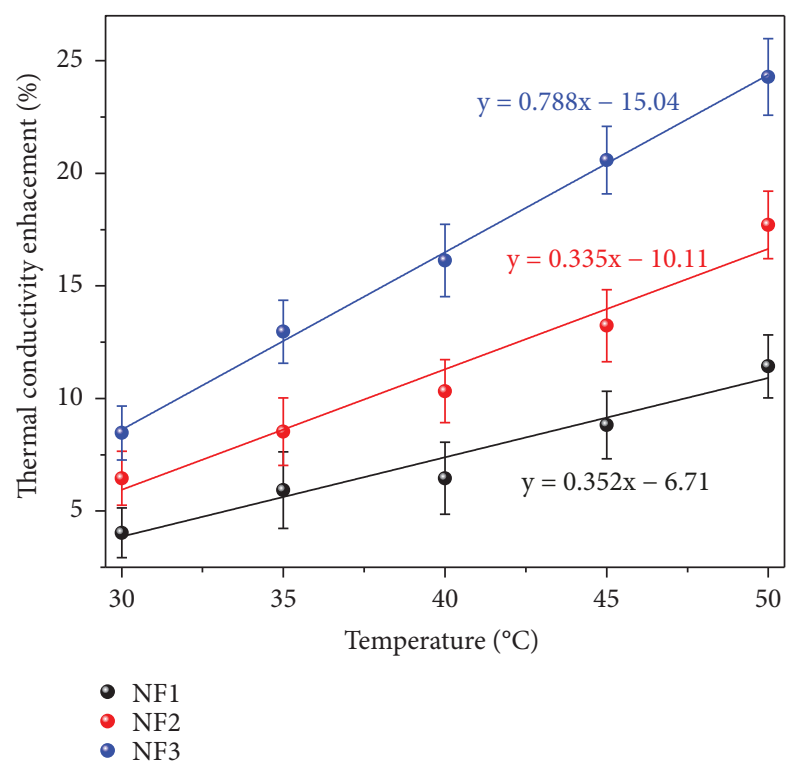

Figure 5

function of different temperatures. As can be seen, the thermal conductivity of nanofluids increases with the increase in MWCNT concentration. This may result from the decrease in the mean free path or thermal transport distance among MWCNTs as the volume fraction increases. According to Baby and Sundara, the decrease in thermal transport distance leads to the increase in the frequency of lattice vibration and thus the thermal conductivity of nanofluids will be improved [29]. The effect of the temperature on the thermal conductivity of nanofluids was also investigated. The experimental results show that the thermal conductivity of nanofluids increases with higher temperatures. By using linear fitting, we can determine the improvement rate of the nanofluid at different temperatures via a slope of the fitting function. As shown in Figure 5, the slopes of thermal conductivity enhancement of nanofluids were estimated to be 0.352 , 0.535 , and 0.788 corresponding to nanofluids NF1, NF2, and NF3, respectively. The obtained results demonstrated that the nanofluid with higher MWCNT concentrations shows a higher improvement rate at all measured temperatures. For example, at $30^{\circ} \mathrm{C}$, the thermal conductivity enhancement of nanofluid NF3 (8.5\%) is higher than that of nanofluid NF1 (4.4\%) and nanofluid NF2 (6.4\%). With the highest measured temperature of $50^{\circ} \mathrm{C}$, the thermal conductivity enhancement value also keeps the same trend but the enhancement value is much different with $11.4 \%$ for nanofluid NF1, $17.7 \%$ for nanofluid NF2, and $24.2 \%$ for nanofluid NF3. This result could be due to the contribution of Brownian motion that plays as a key mechanism of thermal conductivity enhancement of nanofluids [30]. Besides, increasing temperature will lead to a decrease in the formation of nanoadditive clusters in nanofluid due to the reduction of the nanoadditive surface energy and improve the Brownian motion by the reduction of viscosity [31].

Several theoretical models have been proposed to evaluate the thermal conductivity of nanofluids as listed in Table 1
[32-37]. Using the reported values $\left(K_{\mathrm{CNT}} \approx 1800 \mathrm{Wm}^{-1} \mathrm{~K}^{-1}\right.$ [38], $K_{\mathrm{EG}} \approx 0.25 \mathrm{Wm}^{-1} \mathrm{~K}^{-1}$, and $t \approx 2 \mathrm{~nm}$ ) and the calculated values $\left(l_{\mathrm{CNT}}=10 \mu \mathrm{m}, d_{\mathrm{CNT}}=20 \mathrm{~nm}, r_{\mathrm{CNT}}=10 \mathrm{~nm}\right.$, and $n=$ 14) for the theoretical models, the fitting results were plotted and are shown in Figure 6. The estimated data from the Maxwell model and Patel model is much lower or higher than the experimental data. The reason for this could be due to the fact that these models only take into account the influence of $K_{\mathrm{CNT}}, K_{\mathrm{bf}}$, and CNT concentration and do not take the CNT size into consideration. The Hamilton-Crosser (H-C) model shows a better fitting data than other models. This could be due to the fact that the $\mathrm{H}-\mathrm{C}$ model considers not only the effect of the thermal conductivity and concentration but also the CNT size with an empirical shape factor. However, in fact, the thermal conductivity of nanofluid does not depend only on the parameters such as thermal conductivity and concentration of nanoadditives. Some parameters like thermal conductivity and thermal boundary resistance (TBR) of the interfacial layer between CNT and base fluid also need to be considered. The problem here is the difficulty in determining the mentioned parameters by the experimental study. Nan et al. have proposed a model that considered the effect of the TBR on the thermal conductivity of nanofluids [36]. By using the TBR fitting of Nan et al.'s model and the experimental data in our study, the TBR of MWCNTs and EG-based fluid was determined to be $150 \times 10^{-8} \mathrm{~m}^{2} \mathrm{KW}^{-1}$. The interfacial thermal conductivity $\left(K_{i}\right)$ between MWCNT and EG was also calculated to be $1.65 \mathrm{Wm}^{-1} \mathrm{~K}^{-1}$ by using Murshed et al.'s model [37]. The calculated $K_{i}$ value is lower, which is why the thermal conductivity enhancement of nanofluids containing MWCNT$\mathrm{COOH}$ and Tween-80 surfactant is a bit lower compared to other reports $[18,39,40]$. Further studies will be conducted in the near future to improve $K_{i}$ in order to enhance the thermal conductivity of nanofluids.

The photothermal conversion performance of MWCNT/ EG nanofluids is largely dependent on the temperature variations of nanofluids as a function of lighting time. The effects of nanofluid concentration on the temperature variations of nanofluids at the same lighting time are presented in Figure 7. It is clear that a profound improvement in the photothermal conversion property of EG was achieved after the addition of MWCNTs. The nanofluid temperature increased more quickly than that of EG within the lighting time range of $30 \mathrm{~min}$. For example, the highest temperature of nanofluids NF2 and NF3, at the terminal time of $30 \mathrm{~min}$, was increased by about $4.2 \%$ as compared with that of EG. However, the photothermal conversion capability of nanofluid NF2 seems better than that of nanofluid NF3. The detail of photothermal conversion enhancement of nanofluids was shown in Figure 8. As can be seen, nanofluid NF1 reached the stable regime about $2.1 \%$ after $1500 \mathrm{~s}$ lighting that is lower than those of nanofluid NF2 and nanofluid NF3. This is attributed to the lower thermal conductivity as discussed in the above section. Nanofluid NF2 and nanofluid NF3 go to the stable point to be $4.2 \%$. However, nanofluid NF2 reaches the stable regime after $750 \mathrm{~s}$ while nanofluid NF3 needs about $1750 \mathrm{~s}$ to reach the stable regime that even has higher thermal conductivity. This result could be due to 
TABLE 1: Several theoretical models for the thermal conductivity of nanofluids: thermal conductivity $(K)$, CNT concentration $(\varphi)$, empirical shape factor $(n)$, interfacial layer thickness $(t)$, and thermal boundary resistance (TBR).

\begin{tabular}{|c|c|}
\hline Investigator & Formula \\
\hline Maxwell [32] & $\frac{K_{\mathrm{nf}}}{K_{\mathrm{bf}}}=\frac{K_{\mathrm{CNT}}+2 K_{\mathrm{bf}}+2 \varphi\left(K_{\mathrm{CNT}}-K_{\mathrm{bf}}\right)}{K_{\mathrm{CNT}}+2 K_{\mathrm{bf}}-\varphi\left(K_{\mathrm{CNT}}-K_{\mathrm{bf}}\right)}$ \\
\hline Hamilton and Crosser [33] & $\frac{K_{\mathrm{nf}}}{K_{\mathrm{bf}}}=\frac{K_{\mathrm{CNT}}+(n-1) K_{\mathrm{bf}}-(n-1) \varphi\left(K_{\mathrm{bf}}-K_{\mathrm{CNT}}\right)}{K_{\mathrm{CNT}}+(n-1) K_{\mathrm{bf}}+\varphi\left(K_{\mathrm{bf}}-K_{\mathrm{CNT}}\right)}$ \\
\hline Patel et al. [34] & $\frac{K_{\mathrm{nf}}}{K_{\mathrm{bf}}}=1+\frac{K_{\mathrm{CNT}} \varphi r_{\mathrm{bf}}}{K_{\mathrm{bf}}(1-\varphi) r_{\mathrm{CNT}}}$ \\
\hline Xue [35] & $\frac{K_{\mathrm{nf}}}{K_{\mathrm{bf}}}=\frac{1-\varphi+2 \varphi\left(K_{\mathrm{CNT}} /\left(K_{\mathrm{CNT}}-K_{\mathrm{bf}}\right)\right) \ln \left(\left(K_{\mathrm{CNT}}+K_{\mathrm{bf}}\right) / 2 K_{\mathrm{bf}}\right)}{1-\varphi+2 \varphi\left(K_{\mathrm{bf}} /\left(K_{\mathrm{CNT}}-K_{\mathrm{bf}}\right)\right) \ln \left(\left(K_{\mathrm{CNT}}+K_{\mathrm{bf}}\right) / 2 K_{\mathrm{bf}}\right)}$ \\
\hline Nan et al. [36] & $\begin{array}{c}\frac{K_{\mathrm{nf}}}{K_{\mathrm{bf}}}=1+\frac{\varphi l_{\mathrm{CNT}}}{d_{\mathrm{CNT}}} \frac{K_{\mathrm{CNT}} / K_{\mathrm{bf}}}{\left(l_{\mathrm{CNT}} / d_{\mathrm{CNT}}\right)+\left(2 a_{k} / d_{\mathrm{CNT}}\right)\left(K_{\mathrm{CNT}} / K_{\mathrm{bf}}\right)} \\
a_{k}=\mathrm{TBR} \times K_{\mathrm{CNT}}\end{array}$ \\
\hline Murshed et al. [37] & $\begin{array}{c}K_{\mathrm{nf}}=\frac{\left(K_{\mathrm{CNT}}-K_{i}\right) \varphi K_{i}\left(\gamma_{1}^{2}-y^{2}+1\right)+\left(K_{\mathrm{CNT}}+K_{i}\right) \gamma_{1}^{2}\left[\varphi y^{2}\left(K_{i}-K_{\mathrm{bf}}\right)+K_{\mathrm{bf}}\right]}{\gamma_{1}^{2}\left(K_{\mathrm{CNT}}+K_{i}\right)-\left(K_{\mathrm{CNT}}-K_{i}\right) \varphi\left(\gamma_{1}^{2}+y^{2}-1\right)} \\
\gamma_{1}=\frac{1+t}{d_{\mathrm{CNT}}} \\
\gamma=\frac{1+t}{r_{\mathrm{CNT}}}\end{array}$ \\
\hline
\end{tabular}

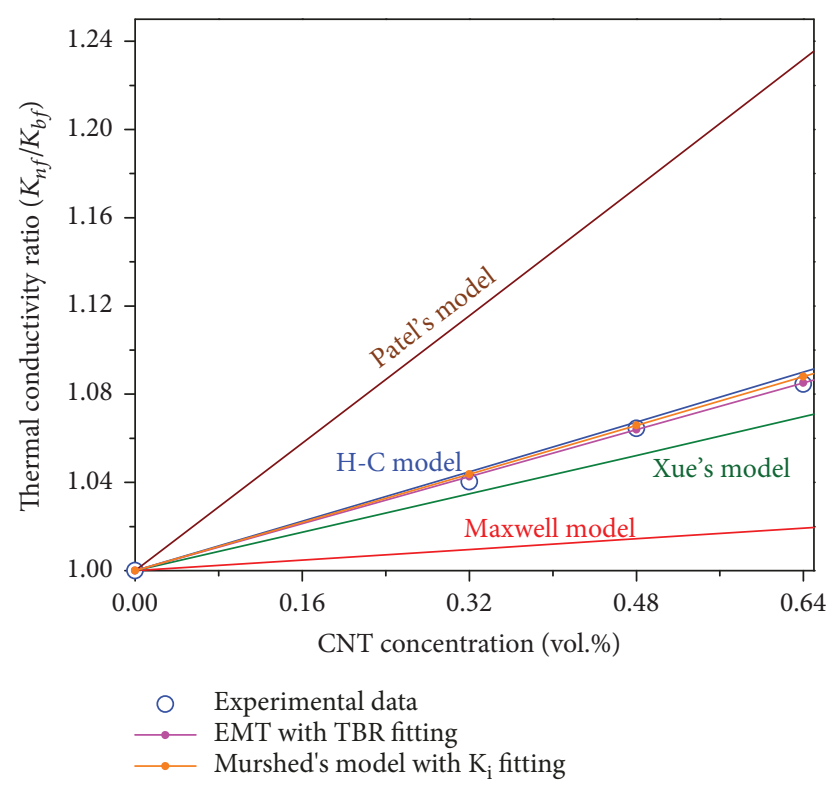

Figure 6

the fact that nanofluid NF2 with higher CNT concentration causes a larger infrared emissivity and hence an increase in heat loss. The excessive concentration can reinforce the volumetric solar energy absorption at a relatively small nanofluid height from the upper surface, and thus more sunlight can be absorbed in the upper part. As a result, the corresponding temperature of aqueous suspension at a larger depth would even be lower than that at a smaller concentration. The same trend has also been reported by $\mathrm{Qu}$ and coworkers in which they investigated the effect of concentration variation of the MWCNT- $\mathrm{H}_{2} \mathrm{O}$ nanofluid on the photothermal conversion [13].

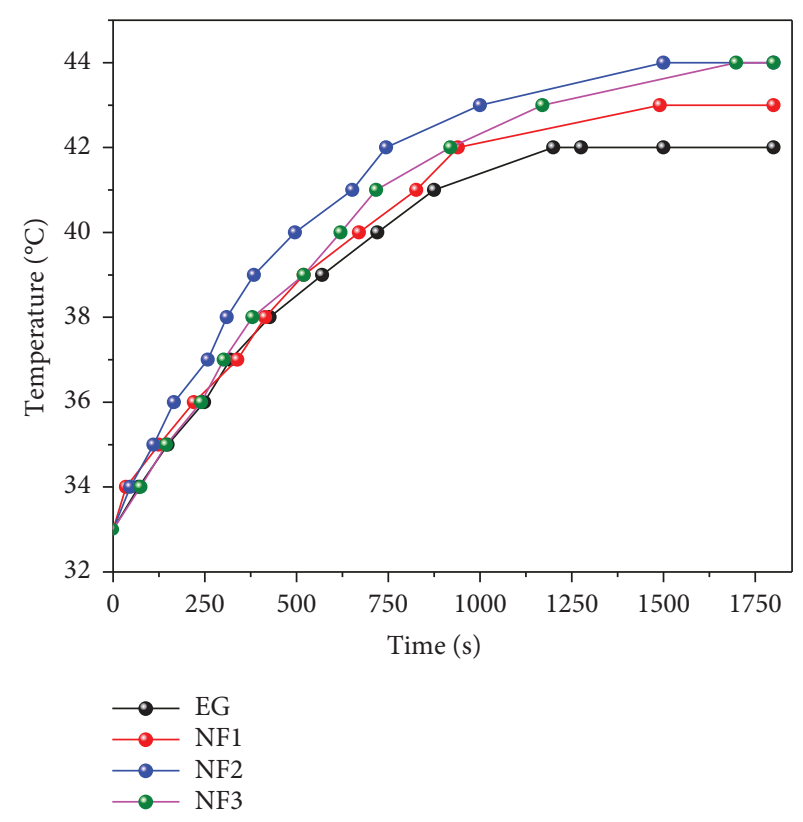

Figure 7

\section{Conclusions}

The successful hydroxyl functionalization of carbon nanotubes was proven by Raman and FTIR spectral measurements. High-stability EG-based nanofluids containing MWCNT$\mathrm{OH}$ were prepared by an ultrasonication method with the Tween-80 surfactant. The nanofluid containing 0.64 vol. $\%$ MWCNT concentration showed a maximum thermal conductivity enhancement about $24 \%$ at $50^{\circ} \mathrm{C}$. The measurement results showed that the lighting absorption efficiency of the nanofluids increases with the optimal concentration 


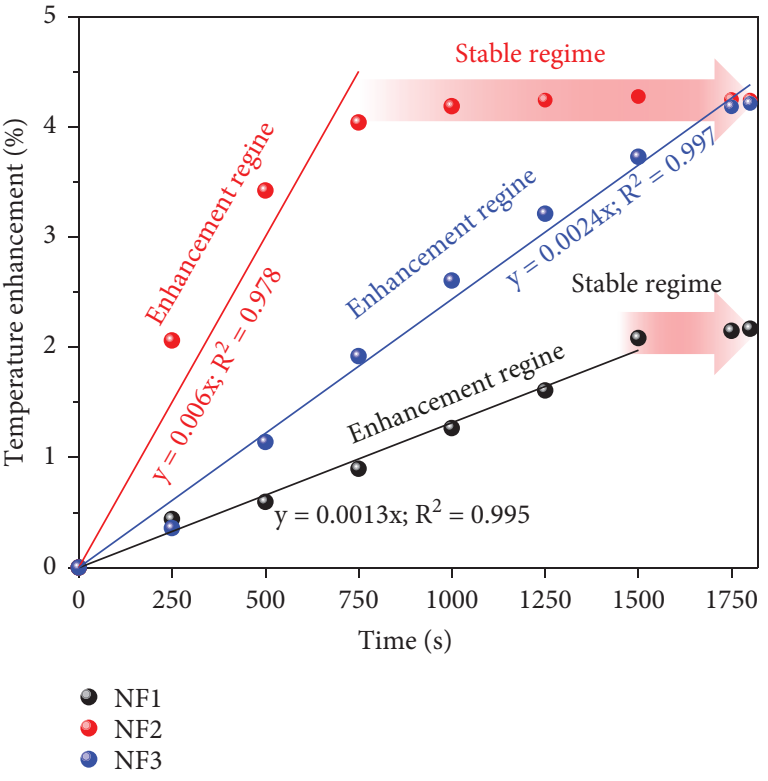

Figure 8

of CNTs in nanofluids about $0.48 \mathrm{vol} . \%$. The temperature of MWCNT/EG nanofluid at concentrations of $0.48 \mathrm{vol} . \%$ and $0.64 \mathrm{vol} . \%$ was increased by about $4.2 \%$ after a $30 \mathrm{~min}$ lighting compared to that of ethylene glycol. These results have opened the potential application of CNTs in nanofluids for solar absorption.

\section{Data Availability}

The data used to support the findings of this study are available from the corresponding author upon request.

\section{Conflicts of Interest}

The authors declare that there is no conflict of interests regarding the publication of this paper.

\section{Acknowledgments}

This research was financially supported by the National Foundation for Science and Technology Development (NAFOSTED) under project no. 103.99-2015.70. This work is also supported by Vietnam Academy of Science and Technology under project no. VAST.TĐ.QP.03/17-19.

\section{References}

[1] P. K. Nagarajan, J. Subramani, S. Suyambazhahan, and R. Sathyamurthy, "Nanofluids for solar collector applications: a review," Energy Procedia, vol. 61, pp. 2416-2434, 2014.

[2] M. Beerepoot, Technology Roadmap Solar Heating and Cooling, International Energy Agency (IEA), Paris, France, 2012.

[3] D. S. Codd, A. Carlson, J. Rees, and A. H. Slocum, "A low cost high flux solar simulator," Solar Energy, vol. 84, no. 12, pp. 2202-2212, 2010.
[4] S. A. Kalogirou, "Solar thermal collectors and applications," Progress in Energy and Combustion Science, vol. 30, no. 3, pp. 231-295, 2004.

[5] L. Vasiliev, E. Hleb, A. Shnip, and D. Lapotko, "Bubble generation in micro-volumes of "nanofluids'," International Journal of Heat and Mass Transfer, vol. 52, no. 5-6, pp. 1534-1539, 2009.

[6] M. Jama, T. Singh, S. M. Gamaleldin et al., "Critical review on nanofluids: preparation, characterization, and applications," Journal of Nanomaterials, vol. 2016, Article ID 6717624, 22 pages, 2016.

[7] S. Lotfizadeh and T. Matsoukas, "Effect of nanostructure on thermal conductivity of nanofluids," Journal of Nanomaterials, vol. 2015, Article ID 697596, 7 pages, 2015.

[8] W. Yu and H. Xie, "A review on nanofluids: preparation, stability mechanisms, and applications," Journal of Nanomaterials, vol. 2012, Article ID 435873, 17 pages, 2012.

[9] M. M. Tawfik, "Experimental studies of nanofluid thermal conductivity enhancement and applications: a review," Renewable and Sustainable Energy Reviews, vol. 75, pp. 1239-1253, 2017.

[10] N. Hordy, D. Rabilloud, J. L. Meunier, and S. Coulombe, "A stable carbon nanotube nanofluid for latent heat-driven volumetric absorption solar heating applications," Journal of Nanomaterials, vol. 2015, Article ID 850217, 6 pages, 2015.

[11] B. H. Thang, P. van Trinh, L. D. Quang, N. T. Huong, P. H. Khoi, and P. N. Minh, "Heat dissipation for the Intel Core i5 processor using multiwalled carbon-nanotube-based ethylene glycol," Journal of the Korean Physical Society, vol. 65, no. 3, pp. 312-316, 2014.

[12] B. H. Thang, P. V. Trinh, N. V. Chuc, P. H. Khoi, and P. N. Minh, "Heat dissipation for microprocessor using multiwalled carbon nanotubes based liquid," The Scientific World Journal, vol. 2013, Article ID 305957, 6 pages, 2013.

[13] J. Qu, M. Tian, X. Han, R. Zhang, and Q. Wang, "Photothermal conversion characteristics of MWCNT- $\mathrm{H}_{2} \mathrm{O}$ nanofluids for direct solar thermal energy absorption applications," Applied Thermal Engineering, vol. 124, pp. 486-493, 2017.

[14] R. C. Shende and S. Ramaprabhu, "Thermo-optical properties of partially unzipped multiwalled carbon nanotubes dispersed nanofluids for direct absorption solar thermal energy systems," Solar Energy Materials \& Solar Cells, vol. 157, pp. 117-125, 2016.

[15] K. Y. Leong, H. C. Ong, N. H. Amer, M. J. Norazrina, M. S. Risby, and K. Z. Ku Ahmad, "An overview on current application of nanofluids in solar thermal collector and its challenges," Renewable and Sustainable Energy Reviews, vol. 53, pp. 1092-1105, 2016.

[16] Babita, S. K. Sharma, and S. M. Gupta, "Preparation and evaluation of stable nanofluids for heat transfer application: a review," Experimental Thermal and Fluid Science, vol. 79, pp. 202-212, 2016.

[17] M. Raja, R. Vijayan, P. Dineshkumar, and M. Venkatesan, "Review on nanofluids characterization, heat transfer characteristics and applications," Renewable and Sustainable Energy Reviews, vol. 64, pp. 163-173, 2016.

[18] P. van Trinh, N. N. Anh, N. T. Tam et al., "Influence of defects induced by chemical treatment on the electrical and thermal conductivity of nanofluids containing carboxyl-functionalized multi-walled carbon nanotubes," RSC Advances, vol. 7, no. 79, pp. 49937-49946, 2017. 
[19] A. Felten, C. Bittencourt, J. J. Pireaux, G. van Lier, and J. C. Charlier, "Radio-frequency plasma functionalization of carbon nanotubes surface $\mathrm{O}_{2}, \mathrm{NH}_{3}$, and $\mathrm{CF}_{4}$ treatments," Journal of Applied Physics, vol. 98, no. 7, article 074308, 2005.

[20] P. A. Song, H. T. Yang, S. Y. Fu et al., "Effect of carbon nanotubes on the mechanical properties of polypropylene/wood flour composites: reinforcement mechanism," Journal of Macromolecular Science, Part B, vol. 50, no. 5, pp. 907-921, 2011.

[21] T. L. do Amaral Montanheiro, F. H. Cristóvan, J. P. B. Machado, D. B. Tada, N. Durán, and A. P. Lemes, "Effect of MWCNT functionalization on thermal and electrical properties of PHBV/MWCNT nanocomposites," Journal of Materials Research, vol. 30, no. 1, pp. 55-65, 2015.

[22] P. V. Trinh, N. V. Luan, D. D. Phuong et al., "Microstructure, microhardness and thermal expansion of CNT/Al composites prepared by flake powder metallurgy," Composites Part A: Applied Science and Manufacturing, vol. 105, pp. 126-137, 2018.

[23] P. V. Trinh, N. N. Anh, N. T. Hong, P. N. Hong, P. N. Minh, and B. H. Thang, "Experimental study on the thermal conductivity of ethylene glycol-based nanofluid containing Gr-CNT hybrid material," Journal of Molecular Liquids, vol. 269, pp. 344-353, 2018.

[24] L. Bokobza and J. Zhang, "Raman spectroscopic characterization of multiwall carbon nanotubes and of composites," Express Polymer Letters, vol. 6, no. 7, pp. 601-608, 2012.

[25] A. C. Ferrari and J. Robertson, "Interpretation of Raman spectra of disordered and amorphous carbon," Physical Review B, vol. 61, no. 20, pp. 14095-14107, 2000.

[26] M. A. Kabbani, C. S. Tiwary, P. A. S. Autreto et al., "Ambient solid-state mechano-chemical reactions between functionalized carbon nanotubes," Nature Communications, vol. 6, no. 1, article 7291, 2015.

[27] A. Ghadimi, R. Saidur, and H. S. C. Metselaar, "A review of nanofluid stability properties and characterization in stationary conditions," International Journal of Heat and Mass Transfer, vol. 54, no. 17-18, pp. 4051-4068, 2011.

[28] J. Ivall, G. Langlois-Rahme, S. Coulombe, and P. Servio, "Quantitative stability analyses of multiwall carbon nanotube nanofluids following water/ice phase change cycling," Nanotechnology, vol. 28, no. 5, article 055702, 2017.

[29] T. T. Baby and R. Sundara, "Synthesis and transport properties of metal oxide decorated graphene dispersed nanofluids," The Journal of Physical Chemistry C, vol. 115, no. 17, pp. 85278533, 2011.

[30] C. H. Chon, K. D. Kihm, S. P. Lee, and S. U. S. Choi, "Empirical correlation finding the role of temperature and particle size for nanofluid $\left(\mathrm{Al}_{2} \mathrm{O}_{3}\right)$ thermal conductivity enhancement," Applied Physics Letters, vol. 87, no. 15, article 153107, 2005.

[31] L. Yu-Hua, Q. Wei, and F. Jian-Chao, "Temperature dependence of thermal conductivity of nanofluids," Chinese physics letters, vol. 25, no. 9, pp. 3319-3322, 2008.

[32] J. C. Maxwell, A Treatise on Electricity and Magnetism, Clarendon, 1973.

[33] R. L. Hamilton and O. K. Crosser, "Thermal conductivity of heterogeneous two-component systems," Industrial \& Engineering Chemistry Fundamentals, vol. 1, no. 3, pp. 187-191, 1962.
[34] H. E. Patel, K. B. Anoop, T. Sundararajan, and S. K. Das, "Model for thermal conductivity of CNT-nanofluids," Bulletin of Materials Science, vol. 31, no. 3, pp. 387-390, 2008.

[35] Q. Z. Xue, "Model for thermal conductivity of carbon nanotube-based composites," Physica B: Condensed Matter, vol. 368, no. 1-4, pp. 302-307, 2005.

[36] C. W. Nan, R. Birringer, D. R. Clarke, and H. Gleiter, "Effective thermal conductivity of particulate composites with interfacial thermal resistance," Journal of Applied Physics, vol. 81, no. 10, pp. 6692-6699, 1997.

[37] S. M. S. Murshed, K. C. Leong, and C. Yang, "Investigations of thermal conductivity and viscosity of nanofluids," International Journal of Thermal Sciences, vol. 47, no. 5, pp. 560568, 2008.

[38] A. A. Balandin, "Thermal properties of graphene and nanostructured carbon materials," Nature Materials, vol. 10, no. 8, pp. 569-581, 2011.

[39] P. van Trinh, N. N. Anh, B. H. Thang et al., "Enhanced thermal conductivity of nanofluid-based ethylene glycol containing $\mathrm{Cu}$ nanoparticles decorated on a Gr-MWCNT hybrid material," RSC Advances, vol. 7, no. 1, pp. 318-326, 2017.

[40] S. Harish, K. Ishikawa, E. Einarsson et al., "Temperature dependent thermal conductivity increase of aqueous nanofluid with single walled carbon nanotube inclusion," Materials Express, vol. 2, no. 3, pp. 213-223, 2012. 


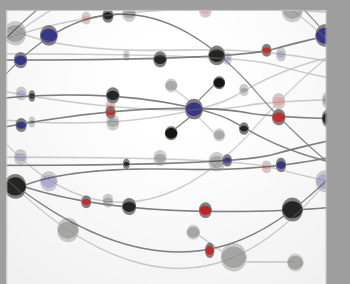

The Scientific World Journal
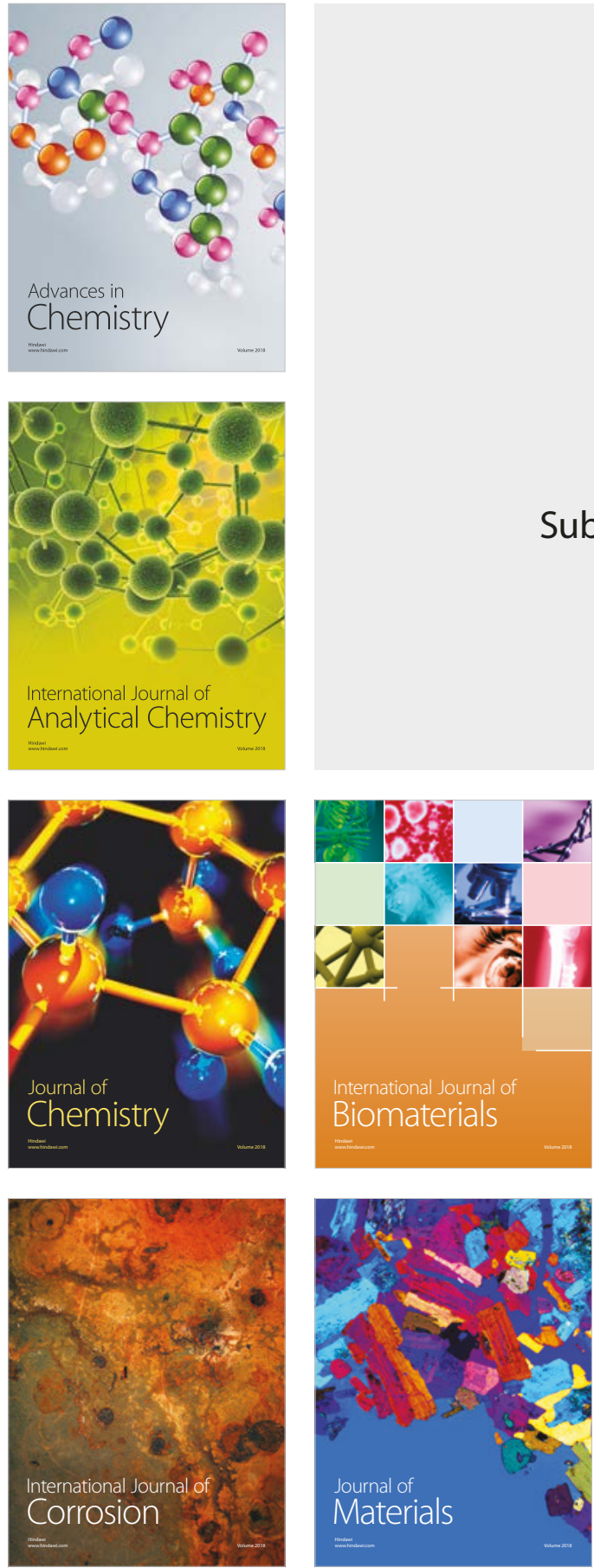

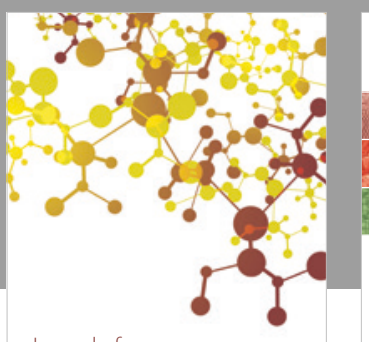

Journal of

Applied Chemistry
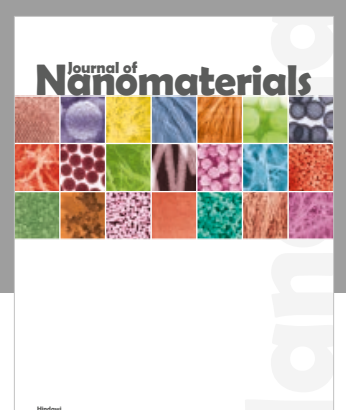

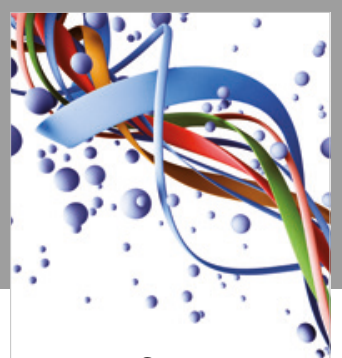

Scientifica

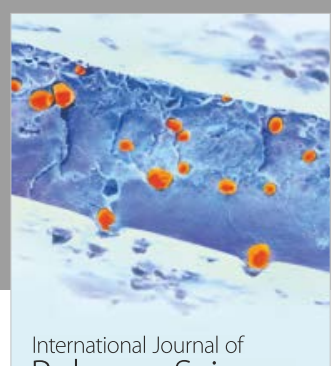

Polymer Science

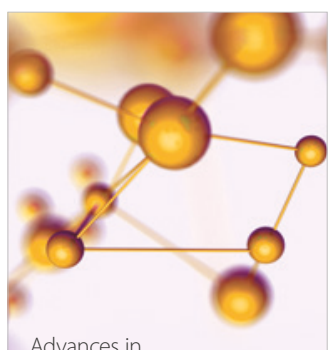

Physical Chemistry
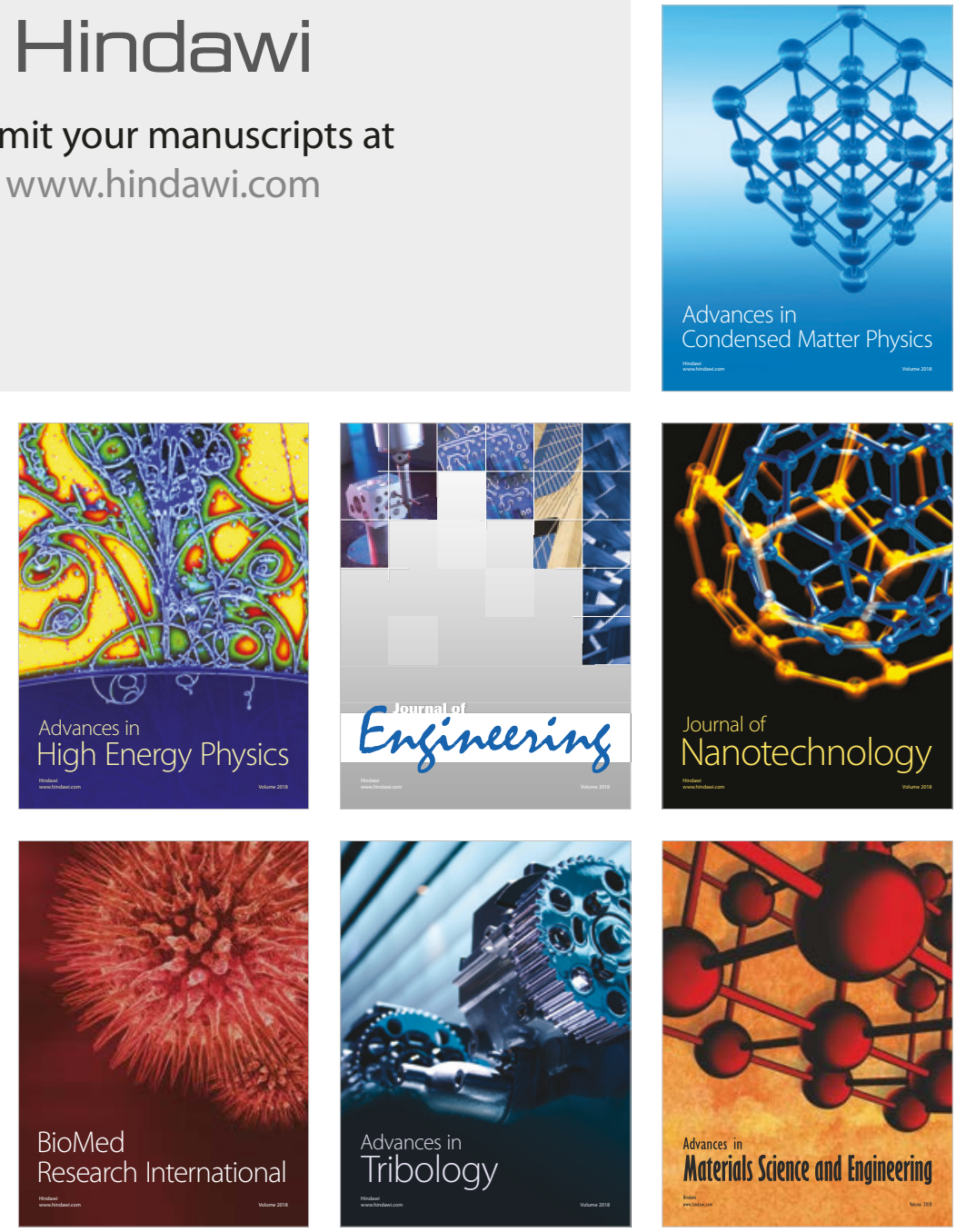